\title{
Strategic Fit In Inter-Organizational Networks: A Life Cycle Framework For The Healthcare IDS
}

Evelyn H. Thrasher, Western Kentucky University, USA

\begin{abstract}
Strategic alliances in the form of inter-organizational networks continue to receive attention in both service and manufacturing industries as a potential form of competitive. The healthcare industry has embraced these strategic alliances with much intensity and perhaps to a greater extent than many other industries. Yet, despite the increasing prevalence of inter-organizational arrangements across most industries, empirical evidence of the value of IT to enhance and support these arrangements is lacking in the IT. Therefore, a need exists to extend IT theory and research to the inter-organizational level of analysis to better meet the needs of contemporary organizations and partnerships. Using the healthcare IDS as the unit of analysis, the primary objective of this study is to stimulate research at the inter-organizational network level of analysis. A conceptual framework of IT value for the inter-organizational network is developed that merges three complementary theoretical concepts, namely the Strategic Alignment Model, the IT-Enabled Business Transformation Framework, and the IT Integration Life Cycle.
\end{abstract}

\section{INTRODUCTION}

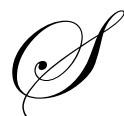

trategic alliances in the form of inter-organizational networks continue to receive attention in both service and manufacturing industries as a potential form of competitive advantage (Payton and Ginzberg, 2001; Straub, Rai et al, 2004). The healthcare industry, in particular, has embraced these strategic alliances with much intensity and perhaps to a greater extent than many other industries. Yet, despite the increasing prevalence of inter-organizational arrangements across most industries, empirical evidence of the value of IT to enhance and support these arrangements is lacking in the IT literature (Melville, Kraemer, and Gurbaxani, 2004). Therefore, a need exists to extend IT theory and research to the inter-organizational level of analysis to better meet the needs of contemporary organizations and partnerships. Due to the increasing development and refinement of interorganizational networks in the healthcare industry over the past decade, the healthcare industry is used as a building block upon which to initiate a research agenda for IT value at the inter-organizational network level of analysis.

In an effort to develop a more efficient, higher quality continuum of patient care, healthcare organizations have formed strategic alliances and partnered to establish collaborative inter-organizational networks called Healthcare Integrated Delivery Systems (IDS). IDSs are defined as integrated strategic alliances of healthcare organizations linked for a common purpose or goal and designed to provide a diversified and comprehensive network of patient care (Young and McCarthy, 1999; Deluca and Enmark, 2002). IDSs provide a valuable opportunity for IT researchers to extend the organizational IT literature to the inter-organizational network level of analysis, a need recognized in the IT literature ((Melville et al, 2004; Straub et al, 2004). Unlike the networks of customers and suppliers common to other industries, the healthcare IDS is an inter-organizational arrangement of stakeholder partnerships in which all participants provide direct services to the patient at the clinical level. In addition, the IDS is viewed as the new healthcare business model and has become the most prevalent network arrangement for healthcare organizations in recent years (Deluca and Enmark, 2002). Thus, the healthcare IDS provides a distinctive resource for inter-organizational network investigation and theory development that may then serve to inform similar research in other industries. 
Despite the efforts of IDSs to provide a high quality continuum of care, a recent study of patient care quality by RAND Corporation (as cited in Straub et al, 2004) indicated that patients received only about $54 \%$ of the needed or recommended care for their particular illness or injury. These results were consistent across all types of care including preventive care, acute care, and chronic condition care. Straub et al (2004) attribute this care provision gap to poor information management and sharing, thus, further illuminating the information management crisis that exists in the healthcare industry. While information management has long been a problem at the firm level (Straub et al, 2004), this study posits that information management issues may be magnified to an even larger degree within the IDS, where streamlined patient care is more reliant on timely, accurate, consolidated information. Thus, while Straub et al (2004) suggest that information technology (IT) may be a key resource for hospitals, this study argues that it should also be a key enabler of clinical integration for the IDS. As the need for sharing, integration, and accuracy of information increases, the need for complementary IT integration and sophistication also increases (Sabherwal and Chan, 1997; Payton and Ginzberg, 2001; Weiner, Savitz, Bernard, and Pucci, 2004).

Using the healthcare IDS as the unit of analysis, the primary objective of the present study is to stimulate research at the inter-organizational network level of analysis. Thus, a conceptual framework of IT value for the IDS is developed that merges three complementary theoretical concepts, namely the Strategic Alignment Model (Henderson and Venkatraman, 1993), the IT-Enabled Business Transformation Framework (Venkatraman, 1994), and the IT Integration Life Cycle (Weiner et al, 2004).

Strategic fit of business and IT strategies has received much attention at the firm level, although only a limited number of prior studies have empirically tested the relationship between strategic alignment and organizational performance. Those studies have consistently demonstrated a positive link between strategic fit and improved firm financial performance; and researchers tend to agree on the importance of strategic fit for organizations (Henderson and Venkatraman, 1993; Venkatraman, 1994; Chan, Huff, Barclay, and Copeland, 1997; Sabherwal \& Chan, 2001). The current study extends the theory of strategic fit to the inter-organizational network, suggesting that strategic fit may be even more critical at the network level. As inter-organizational networks develop and grow, the resulting organizational structures are quite complex, comprised of a number of diverse entities, each bringing its own IT and business strategies. Thus, as these inter-organizational arrangements are formed, it may be necessary for individual firms to compromise and collaborate to establish a unified network strategy. As such, it would seem reasonable, given the complexity of the inter-organizational network, that the network's IT strategy must also be supportive of, and appropriate for, the business strategy and the resulting organizational structure.

Using the theories introduced above and supporting literature, the current study examines the strength of the relationship between strategic fit and IDS performance across different levels of IDS development using a conceptual framework of strategic fit and accompanying profiles. In particular, the following research question is addressed: Does the strength of the relationship between strategic fit and financial and quality performance differ when comparing inter-organizational networks at different levels of development?

This study and the resulting conceptual framework make two important contributions to the IT literature, the first of which regards the unit of analysis. Strategic fit has been researched and empirically supported at the firm level. Thus, unique to the current study is the use of the inter-organizational network as the unit of analysis. Lacking in the IT literature, the need for studies at this level of analysis is recognized by IT researchers (Melville et al, 2004; Straub et al, 2004). Recent studies suggest that, although organizations in virtually all industries are moving to electronic supplier and provider networks, studies of IT value and strategic fit for these networks are lacking (Melville et al, 2004; Straub et al, 2004). As firms in all industries continue to adopt and establish interorganizational networks, it becomes increasingly important for researchers to develop solid, theoretical models to better inform the IT community regarding the value of IT and strategic fit at this level of analysis.

Second, the current study merges the theories of strategic alignment and the integration life cycle and attempts to develop a life cycle framework of strategic fit for the inter-organizational network. In 2004, a call was made for research and manuscripts that would bridge the gap between healthcare IT studies published in the healthcare journals and those published in the IT journals (Wilson and Lankton, 2004). The authors noted a need for 
research that would blend theories and findings from the IT and healthcare reference disciplines to inform both audiences. The current study attempts to answer this call by blending the Strategic Alignment Model (Henderson and Venkatraman, 1993) and IT-Enabled Business Transformation Framework (Venkatraman, 1994) from the IT research literature and the IT Integration Life Cycle (Weiner et al, 2004) from the healthcare literature. These blended theories and a conceptual life cycle framework are used to examine the posited differences in the strength of the relationship between strategic fit and IDS performance across each life cycle stage.

The study begins with an illustration of the anticipated transformational abilities of IT for the IDS. An overview of the theoretical concepts that form the foundation of the framework is provided. Then, a conceptual life cycle framework of strategic fit for the inter-organizational network is proposed. The study concludes with a research agenda, including questions that should be considered in future studies.

\section{POTENTIAL ROLE OF IT IN HEALTHCARE IDS TRANSFORMATION}

Traditional healthcare network structure. The very purpose and nature of work in the healthcare industry requires the sharing of information, resources, and people. Traditionally, this has been accomplished through hybrid arrangements of healthcare providers, each with different roles, organizational structures, and information needs. Like other hybrid arrangements, healthcare networks have been, and continue to be, established to bring synergy to the functions and roles of the key entities for common goals, in this case patient care and reduced costs (Borys and Jemison, 1988). However, traditionally the exchange of patient information and other medical data has been accomplished primarily through manual processes that forced the patient to relay information many times to a number of different organizations, thereby acting as the hub of the network. While the risk associated with multiple data entry points is an important issue among firms in most industries, this risk becomes even more crucial in the healthcare industry where diagnosis and treatment depend upon accurate, consistent patient data (Dowling, 1997; Friedman and Wyatt, 1997). To further complicate the issues, at any given point in time a network entity could be both a partner and a stakeholder in the process depending upon the circumstances of the transaction or the nature of the patient service being provided (Friedman and Wyatt, 1997). Figure 1 depicts the traditional healthcare network as a hub and spoke arrangement linked together primarily by the patient (Rosow and Grimes, 2003).

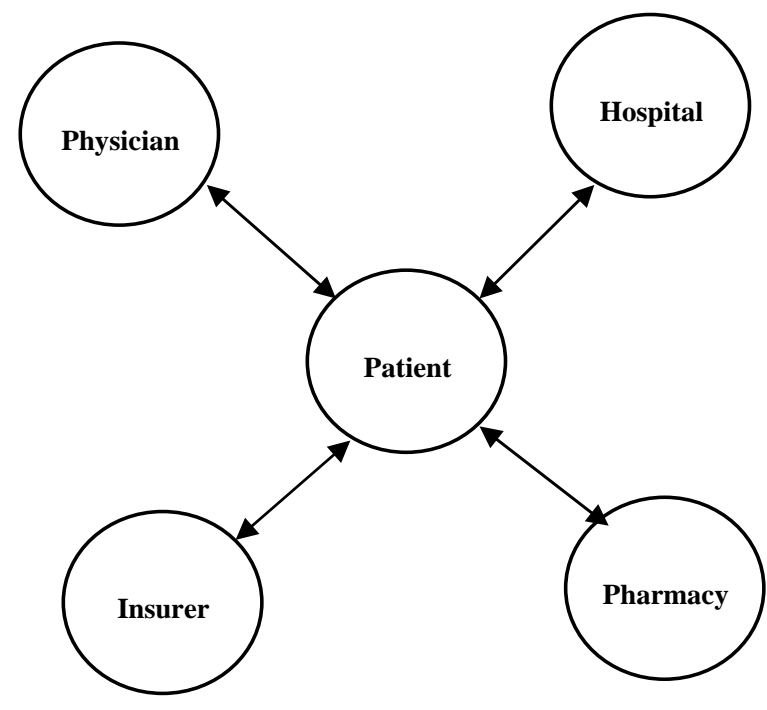

Figure 1: Traditional Healthcare Network Structure

IT-enabled healthcare structure. Researchers tell us that IT has the capability to act as an electronic intermediary, thus, replacing the patient as the hub in the healthcare network structure (Venkatraman, 1994; Weiner 
et al, 2004) (Figure 2). This electronic intermediary should allow for direct inter-organizational links, increased integration among organizations, integrated access to and entry of patient data, and improved information sharing within and among all entities of the healthcare IDS, regardless of function, purpose, or geographic location, with less reliance on information transfer directly from the patient (Venkatraman 1994; Weiner et al, 2004).

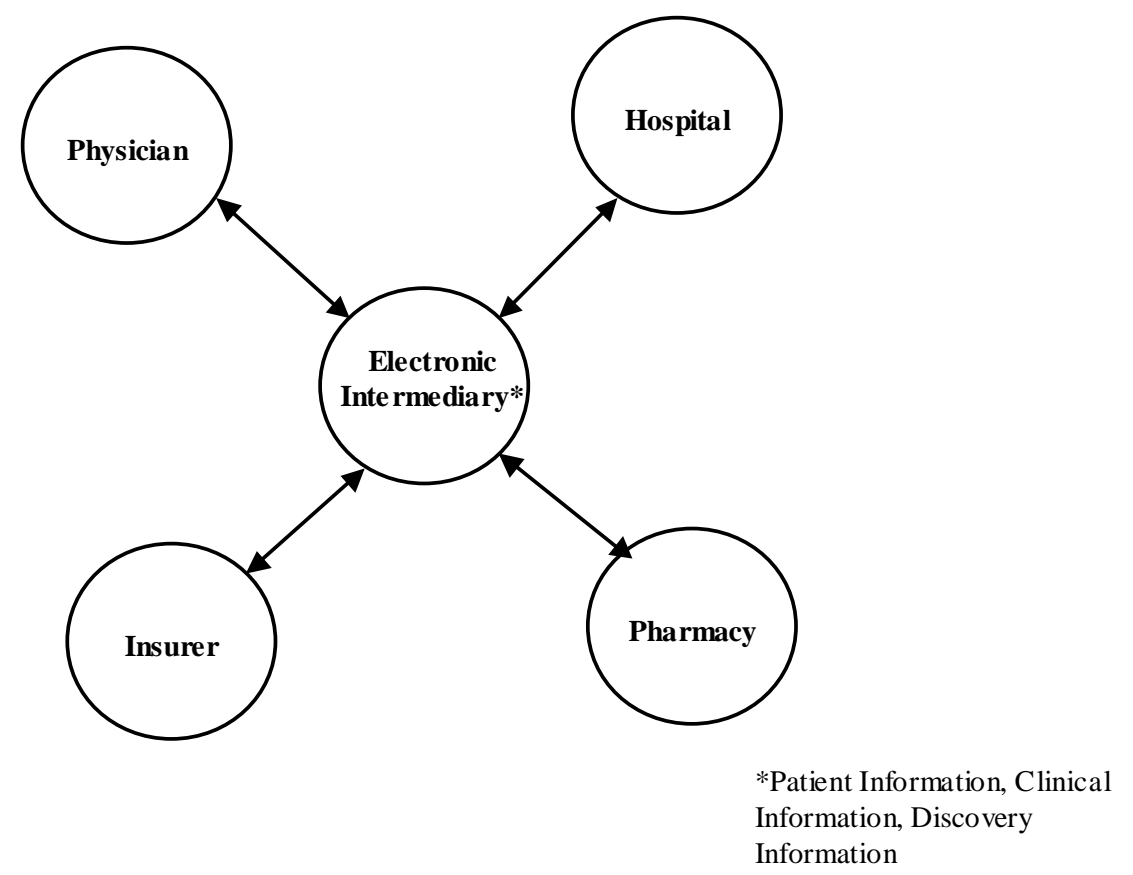

Figure 2: IT-Enabled Healthcare Structure.

In concert with IT integration, healthcare organizations may also implement changes to organizational structure, management structure, and interdependence of processes previously carried out by distinct healthcare organizations. When the result is strategic alignment of IT and business strategies, this alignment seems to increase the overall performance benefits to the organizations above and beyond the benefits realized when IT resources are simply imposed on existing business processes (Henderson and Venkatraman, 1993; Venkatraman, 1994; Chan et al, 1997; Li and Collier, 2000). The ideas of alignment and fit form the foundation of the theories of strategic alignment and the integration life cycle, each of which is further described in the following sections.

\section{STRATEGIC ALIGNMENT OF BUSINESS AND IT}

Henderson and Venkatraman (1993) posited that misalignment of business and IT strategies may have been to blame for the lack of evidence of IT value in many organizations at the time of their research. To better illustrate the complex process of business-IT alignment, the authors proposed an extensive framework called the Strategic Alignment Model (Henderson and Venkatraman, 1993). The foundational theme of this model was the need for fit between the business and IT strategies of an organization, both internally and externally. Past research on strategic alignment had tended to ignore external considerations of strategic market positioning and had dealt only with the internal role of IT to support the operational functions of the organization. Thus, Henderson and Venkatraman (1993) built upon the internal focus of past strategic alignment research and added an external dimension, noting the enabling potential of IT to establish position and competitive advantage in the external marketplace.

In 1994, Venkatraman expanded upon the Strategic Alignment Model with a hierarchical framework of business transformation, further emphasizing the new and important role of IT to promote and lead in the transformation of business processes and organizations, a view not addressed in prior IT research. Labeled the ITEnabled Business Transformation Framework (Figure 3), the framework suggests that the potential role of IT in the 
organization should shift from that of operational business support and automation to one of more strategic leadership in organizational transformation. This new role becomes increasingly important as organizations are transformed and move upward from the evolutionary, or internally-focused, levels to the revolutionary, or externally-focused, levels. The levels of the framework are defined in Table 1.

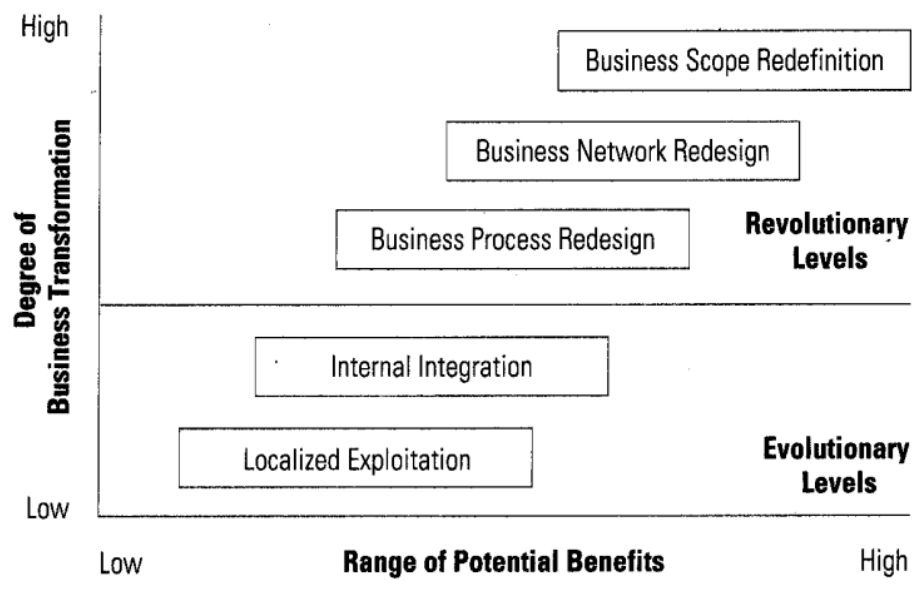

Figure 3: IT-Enabled Business Transformation Framework (Venkatraman, 1994, p. 74).

Evolutionary Levels (Business strategy tends to drive IT strategy)

Revolutionary Levels (IT assumes a stronger role in business strategy formulation)
Localized Exploitation - The first or lowest level of transformation, IT applications are implemented in accordance with existing business structures and are generally viewed as a means to improve efficiency and effectiveness of existing operational processes. Both IT integration and business process transformation are minimal at this level. Most IT applications at this level are standard offerings and are implemented in a stovepipe manner to meet the needs of specific groups within the organization.

Internal Integration - An extension of localized exploitation, IT integration at this level is still considered primarily in support of the internal business strategy. More formal IT planning procedures and planning teams are employed in internal integration, and increased interdependence is noted among the groups within the organization. At this level of transformation, we begin to see IT applications such as database management systems, integrated databases, and Internet, intranet, or extranet technologies.

Business Process Redesign - It is at this level of transformation that organizations begin to look to IT as a possible driver of business process change. In fact, the need for alignment between business and IT strategies is more readily recognized; and the focus begins to shift from a purely internal focus to also include an external focus. Within business process redesign, IT applications tend to be more current; and emerging IT trends are more favorably considered.

Business Network Redesign - Within this level of transformation, the focus on external trading partners and business networks comes to the forefront. Organizations at this level recognize that IT integration alone is insufficient to realize significant benefits among the business network participants. Decision-making, business processes, and value-added services are increasingly integrated to balance the IT capabilities deployed within the network. IT applications and resources at this level allow for unstructured information exchange across functional and geographical boundaries.

Business Scope Redefinition - The most extensive of the transformation levels, business scope redefinition involves the use of IT to redefine the activities within the business network. Elimination of duplicate tasks among business network participants occurs at this level; and increased restructuring of the business network occurs. Coordination and decision-making are centralized at this level to balance the high levels of IT integration across the participating organizations. IT value is greatest at this level of transformation, assuming the organizational structure is in line with the IT capabilities.

Table 1: Definitions of IT-Enabled Business Transformation Framework Levels (Venkatraman, 1994). 
Inherent in both the Strategic Alignment Model and the IT-Enabled Business Transformation Framework is the view of strategic alignment as a dynamic process of adaptation and change rather than a static event. Henderson and Venkatraman (1993) suggested that the ability to innovate and leverage IT resources for continuous differentiation was more effective for organizational success than the development of a specific portfolio of static IT functionality. Further, the authors argued that the driving force for organizational transformation in a firm may shift from the business strategy to the IT strategy and vice versa over time. However, regardless of the driving force, the key is to ensure that fit between business and IT strategy is renewed in a timely manner if improved organizational performance is to be more fully realized at different levels of transformation (Henderson and Venkatraman, 1993; Venkatraman, 1994; Chan et al, 1997).

\section{INTEGRATION LIFE CYCLE}

Life cycle models have been used for a number of years throughout the organizational and IT literature. As Savitz, Kaluzny, and Kelly (2000) note, life cycles were originally adapted from the natural sciences, but have taken many forms in management research, from product life cycles to IT project life cycles to a myriad of other forms. Informed by innovation theory and organization theory, Weiner et al (2004) developed the integration life cycle based on the premise of a recursive relationship between integration and organizational learning (Figure 4). Like Henderson and Venkatraman (1993), Weiner et al (2004) emphasized the need for fit between IT integration and organizational structure at each stage of the life cycle.

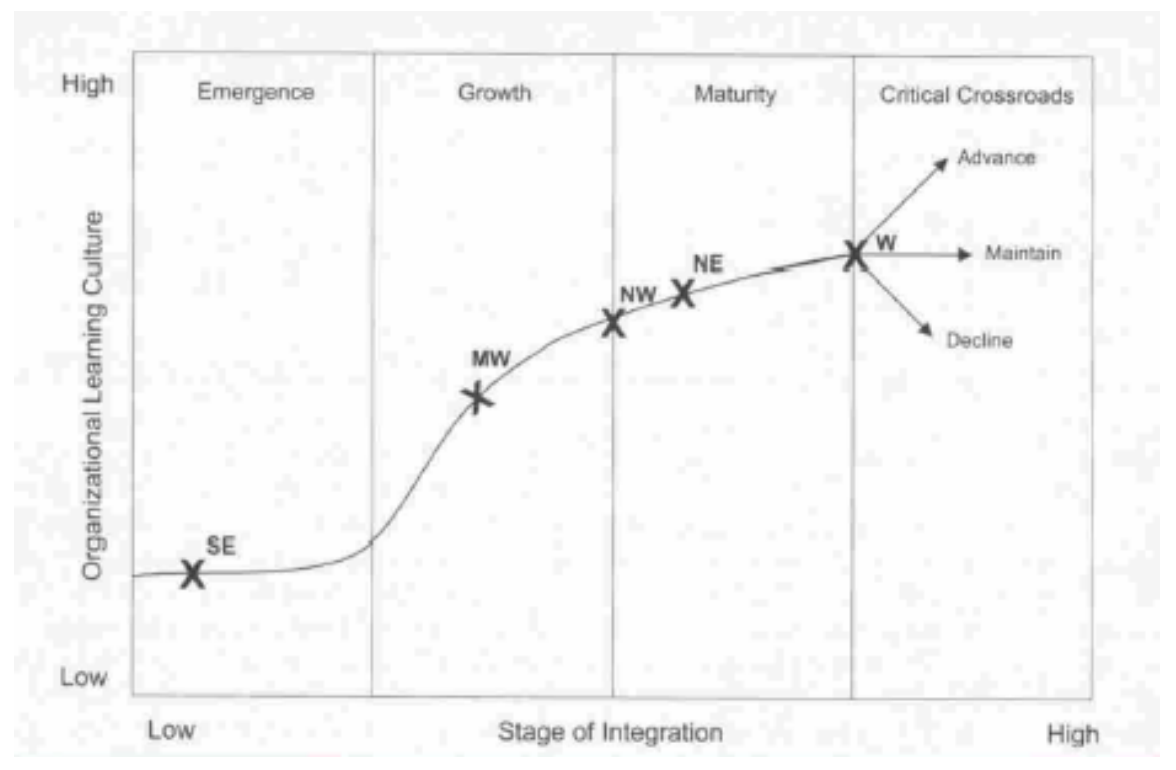

Figure 4: Integration Life Cycle (Weiner et al, 2004, p.55).

In their work on IT planning and implementation, Weiner et al (2004) adapted the prior work of Savitz et al (2000) to describe four stages of development across the integration life cycle - emergence, growth, maturity, and critical crossroads. The authors then extended these stages from an organizational focus to an inter-organizational network focus, as defined in Table 2. Organizational learning and integration within the IDS are posited to follow a positive, nonlinear S-shaped curve, suggesting that as integration increases, interdependence and tolerance for change among organizations also increase and vice versa. Moreover, inter-organizational networks in later stages of the life cycle tend to realize greater IT value than those in earlier stages (Weiner et al, 2004). 


\begin{tabular}{|l|l|}
\hline Emergence & $\begin{array}{l}\text { Users have very limited experience with integration and innovation. The organization is beginning the } \\
\text { transition toward change (Savitz et al, 2000). Also in this phase, IT decision-making is decentralized; and IT } \\
\text { is viewed as business support rather than a strategic tool (Weiner et al, 2004). }\end{array}$ \\
\hline Growth & $\begin{array}{l}\text { This phase is characterized by rapidly increasing levels of tolerance for and willingness to change, as a result } \\
\text { of successful innovations in the emergence phase (Savitz et al, 2000). IT planning appears to still be primarily } \\
\text { decentralized with increasing levels of integration across groups within the organization. Organizations in this } \\
\text { phase are beginning to recognize IT's potential as a strategic resource (Weiner et al, 2004). }\end{array}$ \\
\hline Maturity & $\begin{array}{l}\text { Organizations have generally reached a sustained level of change tolerance, and numerous innovations have } \\
\text { been successfully implemented (Savitz et al, 2000). IT is viewed as a strategic resource, and IT planning and } \\
\text { control are more centralized than in earlier phases (Weiner et al, 2004). }\end{array}$ \\
\hline $\begin{array}{l}\text { Critical } \\
\text { Crossroads }\end{array}$ & $\begin{array}{l}\text { This phase is important in that it represents the point in time when the organization must make a decision to } \\
\text { continue advancement of integration and change, maintain a status quo, or decline in its efforts to integrate and } \\
\text { change (Savitz et al, 2000). IT planning and control are centralized and well-established; user-led innovation } \\
\text { is common; and new opportunities for change and innovation are sought (Weiner et al, 2004). }\end{array}$ \\
\hline
\end{tabular}

Table 2: Phases of Integration Life Cycle.

\section{DEVELOPMENT OF THE STRATEGIC FIT LIFE CYCLE FRAMEWORK}

Merging the theories of strategic alignment and the IDS integration life cycle, this study proposes a conceptual framework of strategic fit for inter-organizational networks (Figure 5). The study proposes that strategic fit has a greater impact on inter-organizational network performance in the later stages of development than in the earlier stages. Attention is focused on the stages of emergence, growth, and maturity. Critical crossroads represents a point in the life cycle of the inter-organizational network when choices must be made as to whether to remain static, to further innovate and change, or to begin to decline and dissolve the network structure. Thus, while critical crossroads certainly represents a pivotal stage in the life cycle of an inter-organizational network, the study focuses on the three stages within which the IDS is still expanding, innovating, and integrating, thereby leaving the critical crossroads stage for future research.

Table 3 summarizes a profile of each life cycle stage. The attributes that comprise each profile have been identified from the works of Venkatraman (1994), Savitz et al (2000), and Weiner et al (2004) and represent attributes of the foundational theories and models used to develop the strategic fit life cycle framework presented in the current study. Further, Payton and Ginzberg (2001), in their work on clinical health information network implementation, also identified system planning, appropriate IT resources to meet business needs, and organizational readiness as significant indicators of IT implementation success. Thus, the current study proposes that these profiles of strategic fit, incorporating both IT and business perspectives, contribute to more significantly improved IDS performance in later development stages. The profile attributes are: 1) IT purpose, 2) tolerance for change, 3) centralization of business and IT management, and 4) formalization of business and IT planning. Each of these attributes serves in concert to enhance the ability of strategic fit to render IDS performance improvements, with greater improvements expected in the late growth and maturity stages.

While research supports the idea that strategic fit at any level of development should improve organizational performance beyond that of IT investment or business transformation in isolation, our framework suggests that the potential value of strategic fit is even greater in later life cycle stages than in earlier stages as a result of differences among these four attributes. Organizational structure, presented in column 1 of table 3 simply describes the structure and configuration of the IDS in terms of geographic reach, comprehensiveness of services provided, and diversity. Then, each of the four supporting attributes describes a part of the IDS profile necessary for achieving strategic fit within each life cycle stage. These four attributes are further developed in the next sections and are used to inform our research question and corresponding propositions. 


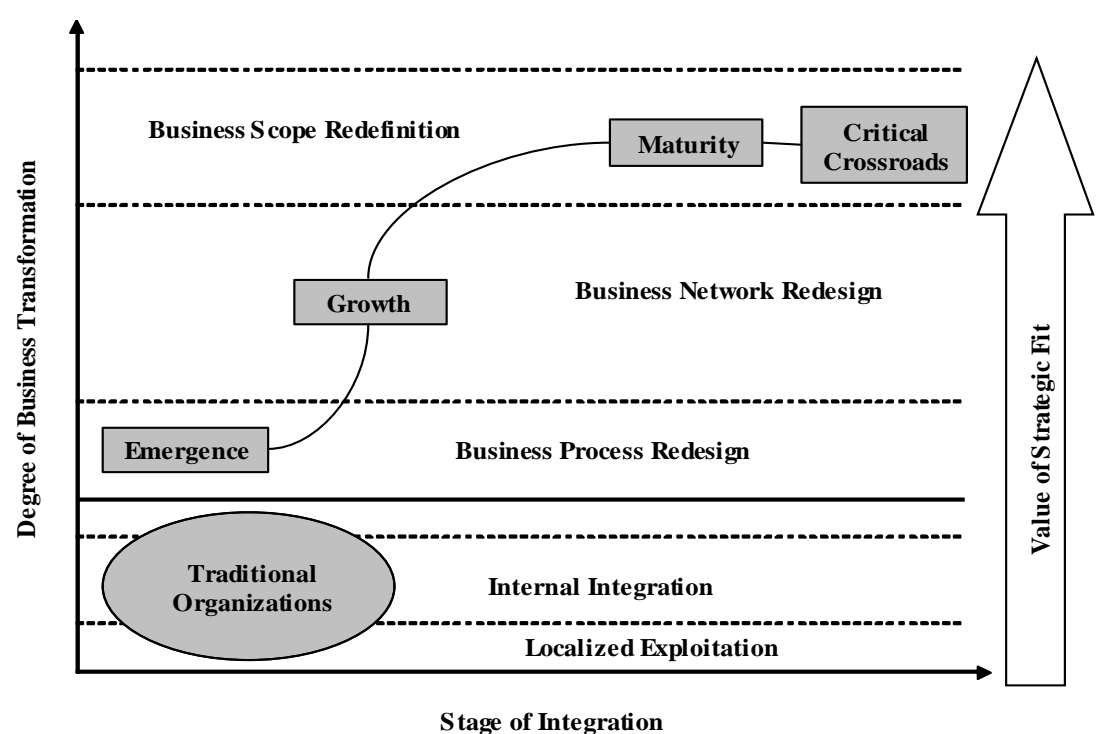

Figure 5: Life Cycle Framework of Strategic Fit Value for the Inter-organizational Network.

IT purpose is defined as the strategic use of IT to support and enable the organizational structure and business process goals of an IDS within a particular life cycle stage. Ndede-Amadi (2004) suggested that simply increasing monetary investments in IT will rarely result in organizational performance improvements; rather it is strategic IT investment, or investment in appropriate IT resources, that is critical for enabling strategic alignment. In the same vein, Venkatraman (1994) notes that simply implementing inter-organizational systems without regard for their appropriateness and fit with the current and planned business processes of the firm will not lead to performance improvements.

Lending support to the arguments presented below, in their 2001 study of alignment between business and IT strategies, Sabherwal and Chan pulled from the Miles and Snow (1978) business strategy typologies of Defender, Prospector, and Analyzer to develop an IT profile most suitable for each business strategy. The authors then tested the correlation between business-IT strategic alignment for each profile and found that strategic alignment in firms with a Defender profile failed to show a significant relationship with business performance improvements, while alignment in each of the other categories was significantly related to business performance. More specifically, lack of empirical support was found for a relationship between alignment and business performance among those firms with a narrow business focus, a primary goal of operational efficiency, and few core services and technologies. Moreover, regarding IT strategies within these firms, IT was primarily viewed as a support tool for obtaining efficiency in operational and daily transactional processes. 


\begin{tabular}{|c|c|c|c|c|c|}
\hline & IDS Structure & IT Purpose & $\begin{array}{l}\text { Tolerance for } \\
\text { Change }\end{array}$ & $\begin{array}{l}\text { Centralization of IT } \\
\text { and Business } \\
\text { Management }\end{array}$ & $\begin{array}{l}\text { Formalization of IT } \\
\text { and Business } \\
\text { Planning }\end{array}$ \\
\hline \multirow[t]{2}{*}{ 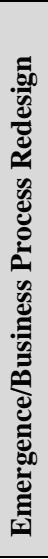 } & $\begin{array}{l}\text { - First step in IDS } \\
\text { development } \\
\text { - Shift in focus from } \\
\text { internal to external } \\
\text { strategies/structures } \\
\text { - IDS is relatively small } \\
\text { and homogeneous } \\
\text { - Minimal emphasis on } \\
\text { strategic fit at IDS level } \\
\text { - Distribution of business } \\
\text { processes across } \\
\text { network participants } \\
\text { remains intact }\end{array}$ & $\begin{array}{l}\text { - Operational support } \\
\text { for business } \\
\text { processes and daily } \\
\text { tasks }\end{array}$ & $\begin{array}{l}\text { - Learning culture is } \\
\text { in its infancy } \\
\text { - Resistance to } \\
\text { change is high }\end{array}$ & $\begin{array}{l}\text { - IT management } \\
\text { decentralized \& } \\
\text { autonomous across } \\
\text { participants } \\
\text { - Business } \\
\text { management } \\
\text { decentralized \& } \\
\text { autonomous across } \\
\text { participants } \\
\text { - Low to no } \\
\text { centralization of IT } \\
\text { or business } \\
\text { management }\end{array}$ & $\begin{array}{l}\text { - IT planning } \\
\text { autonomous across } \\
\text { participants } \\
\text { - Business planning } \\
\text { autonomous across } \\
\text { participants } \\
\text { - IT integration } \\
\text { across participants } \\
\text { is minimal if } \\
\text { present at all }\end{array}$ \\
\hline & $\begin{array}{l}\text { Venkatraman } 1994 \\
\text { Young \& McCarthy } 1999 \\
\text { Savitz, et al } 2000\end{array}$ & $\begin{array}{l}\text { Sabherwal \& Chan } \\
2001\end{array}$ & $\begin{array}{l}\text { Savitz et al } 2000 \\
\text { Weiner et al } 2004\end{array}$ & $\begin{array}{l}\text { Venkatraman } 1994 \\
\text { Weiner et al } 2004\end{array}$ & $\begin{array}{l}\text { Venkatraman } 1994 \\
\text { Weiner et al } 2004\end{array}$ \\
\hline \multirow[t]{2}{*}{ 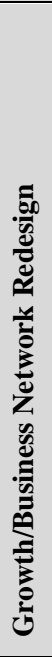 } & $\begin{array}{l}\text { - IDS growing in reach } \\
\text { and scope } \\
\text { - Primary focus on } \\
\text { external trading partners } \\
\text { and network structure } \\
\text { - Increased diversity of } \\
\text { network participants and } \\
\text { services offered } \\
\text { - Strategic fit viewed as a } \\
\text { potential source of } \\
\text { competitive advantage } \\
\text { for the IDS }\end{array}$ & $\begin{array}{l}\text { - Support of } \\
\text { organizational and } \\
\text { process flexibility, } \\
\text { external focus, and } \\
\text { increased innovation } \\
\text { - Interconnection and } \\
\text { integration of } \\
\text { structured business } \\
\text { processes } \\
\text { - Appropriate systems } \\
\text { include market } \\
\text { information systems, } \\
\text { strategic decision } \\
\text { support systems }\end{array}$ & $\begin{array}{l}\text { - Organizational } \\
\text { learning is rapidly } \\
\text { increasing } \\
\text { - Moderate level of } \\
\text { tolerance for } \\
\text { change and } \\
\text { innovation } \\
\text { - Acceptance that IT } \\
\text { integration alone is } \\
\text { insufficient for } \\
\text { success }\end{array}$ & $\begin{array}{l}\text { - Moderate level of } \\
\text { integration of IT } \\
\text { decision-making, } \\
\text { resources, and } \\
\text { value-added } \\
\text { services } \\
\text { - Moderate level of } \\
\text { integration of } \\
\text { business decision } \\
\text { making and } \\
\text { business processes } \\
\text { - Moderate level of } \\
\text { centralization of } \\
\text { both IT and } \\
\text { business } \\
\text { management }\end{array}$ & $\begin{array}{l}\text { - Moderate } \\
\text { interdependence } \\
\text { and coordination } \\
\text { of IT resources } \\
\text { across participants } \\
\text { - Moderate } \\
\text { interdependence } \\
\text { and coordination } \\
\text { of business } \\
\text { planning across } \\
\text { network } \\
\text { participants } \\
\text { - Moderate } \\
\text { "systems" thinking }\end{array}$ \\
\hline & $\begin{array}{l}\text { Venkatraman } 1994 \\
\text { Young \& McCarthy } 1999 \\
\text { Savitz et al } 2000\end{array}$ & $\begin{array}{l}\text { Venkatraman } 1994 \\
\text { Weiner et al } 2004\end{array}$ & $\begin{array}{l}\text { Venkatraman } 1994 \\
\text { Weiner et al } 2004\end{array}$ & $\begin{array}{l}\text { Venkatraman } 1994 \\
\text { Weiner et al } 2004\end{array}$ & $\begin{array}{l}\text { Venkatraman } 1994 \\
\text { Weiner et al } 2004\end{array}$ \\
\hline \multirow{2}{*}{ 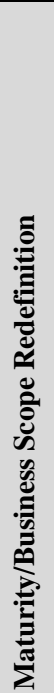 } & $\begin{array}{l}\text { - IDS is more } \\
\text { comprehensive with a } \\
\text { full range of delivery } \\
\text { entities and a large } \\
\text { geographic reach } \\
\text { - Focus on centralized } \\
\text { control and elimination } \\
\text { of duplicate tasks } \\
\text { - Strategic fit is a priority }\end{array}$ & $\begin{array}{l}\text { - Primary focus on } \\
\text { interorganizational/ } \\
\text { enterprise systems } \\
\text { - Sophisticated IT } \\
\text { infrastructure across } \\
\text { IDS } \\
\text { - High IT usage } \\
\text { - Focus on elimination } \\
\text { of duplicate tasks } \\
\text { and multiple data } \\
\text { entry } \\
\text { - Appropriate systems } \\
\text { include enterprise } \\
\text { resource planning, } \\
\text { clinical information } \\
\text { systems }\end{array}$ & $\begin{array}{l}\text { - High level of } \\
\text { comfort among } \\
\text { IDS participants } \\
\text { regarding business } \\
\text { interactions and } \\
\text { processes } \\
\text { - High level of } \\
\text { tolerance for } \\
\text { change and } \\
\text { innovation } \\
\text { - User-led IT and } \\
\text { business innovation } \\
\text { becomes } \\
\text { increasingly } \\
\text { common }\end{array}$ & $\begin{array}{l}\text { - IT management } \\
\text { heavily centralized, } \\
\text { tightly integrated } \\
\text { - Business } \\
\text { management } \\
\text { heavily centralized, } \\
\text { tightly integrated } \\
\text { - Generally } \\
\text { characterized by } \\
\text { the formation of an } \\
\text { executive } \\
\text { management team } \\
\text { charged with IDS } \\
\text { oversight and } \\
\text { control }\end{array}$ & $\begin{array}{l}\text { - Formal procedures } \\
\text { exist for both IT } \\
\text { and business } \\
\text { planning } \\
\text { - IT strategic } \\
\text { planning is } \\
\text { conducted by a } \\
\text { formal steering } \\
\text { team } \\
\text { - High level of } \\
\text { "systems" thinking } \\
\text { - High regard for } \\
\text { user input and } \\
\text { participation in IT } \\
\text { planning }\end{array}$ \\
\hline & $\begin{array}{l}\text { Venkatraman } 1994 \\
\text { Young \& McCarthy } 1999 \\
\text { Savitz et al } 2000 \\
\text { Weiner et al } 2004\end{array}$ & $\begin{array}{l}\text { Venkatraman } 1994 \\
\text { Savitz et al } 2000 \\
\text { Weiner et al } 2004\end{array}$ & $\begin{array}{l}\text { Venkatraman } 1994 \\
\text { Weiner et al } 2004\end{array}$ & $\begin{array}{l}\text { Venkatraman } 1994 \\
\text { Young \& McCarthy } \\
1999 \\
\text { Weiner et al } 2004\end{array}$ & $\begin{array}{l}\text { Venkatraman } 1994 \\
\text { Savitz et al } 2000 \\
\text { Weiner et al } 2004\end{array}$ \\
\hline
\end{tabular}

Table 3: Profile of Strategic Fit for Each Life Cycle Stage. 
As summarized in Table 3 above, the profiles of Sabherwal and Chan (2001) and Miles and Snow (1978) can be linked to the IT profile for each life cycle stage in the strategic fit framework. Similar to Defender firms, IT use for operational efficiency seems most appropriate for those IDSs in the emergence stage where the focus is narrow, the range of services is small, and little diversity exists among the network participants. Sabherwal and Chan (2001) suggest that operational support systems are most appropriate at this stage due to their support of routine, daily transactional processes. Those IDSs in the growth stage are most similar to Prospector firms, with an increasing focus on research and development and innovation and an increasing effort toward expansion of services and geographic reach; thus, IT for flexibility is probably most appropriate at this stage. Sabherwal and Chan (2001) define IT for flexibility as systems such as market information systems and other strategic support systems that allow for flexibility and quick strategic decision-making. Finally, linking mature IDSs to an Analyzer strategy with a more formalized business structure, greater centralization of governance, and an increased focus on stability, Sabherwal and Chan (2001) suggest that IT for comprehensiveness is most important for this stage due to the need for coordination of various business functions across multiple partners, the complexity of the organizational structure, and the need to still maintain efficiency. Inter-organizational systems and enterprise resource planning systems may be most appropriate for this stage.

The findings of Sabherwal and Chan (2001) suggest that strategic fit in the late growth and maturity stages of IDS development should influence IDS performance more positively than would be observed in the emergence phase. Expanding this further, while a statistical comparison was not made between the strengths of the correlations across the categories, the correlation coefficients for Analyzers were greater than those for Prospectors, indicating that strategic alignment may benefit firm performance most significantly among Prospector firms (Sabherwal and Chan, 2001). This would then suggest that the greatest performance benefits should be realized when strategic fit is obtained in a mature IDS.

In a case study of strategic fit within a single IDS, Wickramasinghe and Ginzberg (2001) examined the use of enterprise wide IT systems to facilitate alignment of administrative and physician goals. The authors noted the importance of maintaining congruence and unity among the decision-making entities of the IDS. In particular, healthcare IDS administrators have a goal of high quality healthcare at lower costs; however, physicians generally place more emphasis on high quality healthcare, often to the detriment of cost reduction. To better enable physicians, as primary care decision makers, to align their decisions with the goals of the IDS, enterprise wide automated medical records were implemented and evaluated. The results of the implementation included significant cost savings to the IDS, higher physician satisfaction with the IT resources, and more effective, efficient patient care as measured by reduced mortality rates. These findings lend further support to the idea that IDSs in late growth or maturity stages are likely to see greater performance benefits than emerging and early growth IDSs due to the appropriateness of enterprise wide IT systems for business strategy support in the later life cycle stages.

Smith and Swinehart (2001) investigated the value to a regional IDS of a new IT application designed to analyze patient survey data. In choosing the application, it was important that the application be sufficiently flexible to support the organizational strategy of the IDS. The needs of the organization warranted an inter-organizational system that would provide data analysis in a variety of formats with the ability to analyze data for each stakeholder over a number of different time periods from a single interface. Resulting from implementation of the new patient satisfaction system, several organizational changes have been implemented in areas, such as critical care, the emergency room, outpatient services, and the like. In turn, patient satisfaction has improved dramatically, and the IDS received an award for quality (Smith and Swinehart, 2001). This study posits that inter-organizational systems of the type described above and the related organizational changes and improvements are probably most likely in maturity or late growth stages as opposed to emergence or early growth, due to enterprise wide initiatives, the emphasis on flexibility, and the desire for performance analysis and extensive organizational change.

Finally, in a more recent study, Ndede-Amadi (2004) attributes increased IDS performance in more sophisticated organizations to the implementation and diffusion of enterprise resource planning (ERP), depicted in Table 3 as an appropriate IT application for mature IDSs. As the author suggests, an ERP can act as both a support tool for existing business structures and processes; and, in addition, an ERP can serve as a catalyst for organizational change. Thus, in the case of IDSs, implementation and diffusion of an ERP may enable the IDS to take advantage 
of new opportunities for growth and improved alignment, thus, resulting in even greater performance improvement. On the other hand, IDSs in earlier stages of development are more likely to use IT applications as support tools for existing structures and processes rather than as a means to enable and promote organizational change (Venkatraman, 1994; Sabherwal and Chan, 2001; Ndede-Amadi, 2004). Thus, although strategic alignment of these IT applications with the existing business strategy may be well-established, performance improvements from strategic fit may not be as dramatic as that anticipated in mature IDSs (Ndede-Amadi, 2004).

Tolerance for change is defined as the level of willingness among IDS participants to accept and participate in strategic IT and organizational change. As the framework suggests, tolerance for change is expected to be at a moderate level in the growth stage but greatest in the mature stage, as the network participants in these stages have experienced successful change over time and have gained expertise and confidence with the IT resources and organizational processes. This study suggests that tolerance for change is a critical attribute of strategic fit in that it may serve as a proxy for the level of user support for business and IT strategic change within the IDS, thus, impacting the success and achievement of strategic fit.

Although a number of researchers over the past decade (Barua, Kriebel, and Mukhopadhyay, 1995; Chan et al, 1997; Byrd, Thrasher, Lang, and Davidson, 2006) have demonstrated a positive relationship between IT and organizational performance, as Ndede-Amadi (2004) points out, a number of implementations of complex, enterprisewide systems have failed, possibly due to a low tolerance for change. Ndede-Amadi (2004) suggests that simply implementing an enterprise IT system is insufficient for improvements. Instead, it is the combination of enterprise IT systems and well-trained, willing users that can result in improved performance. Thus, it would seem appropriate that these improvements might be increased even more as the comfort level of the IT users continues to increase, ideally leading to active user-led innovation (Payton and Ginzberg, 2001). The same may be said for an organization's ability to make structural and process changes.

Research suggests that over time organizational learning should increase the IDS participants' tolerance for change and enable them to take a more active role in assuring the success of both IT and organizational change (Savitz et al, 2000; Ahadi, 2004; Weiner et al, 2004). In their 2004 study of IT implementation in IDSs, Weiner et al state, "As the healthcare system gains experience with innovation, particularly successful experience, a learning culture develops wherein people value creating, acquiring, and transferring knowledge, become adept at modifying behavior to reflect new knowledge, and demonstrate greater tolerance for change, ambiguity, and experimentation."

Payton and Ginzberg (2001) illuminated the idea of organizational learning in their work on clinical health information network success. Their findings suggested a timeline of events and improvements that would, in the long-term, result in improved business performance as organizational learning occurred and users became more comfortable with the IT resources and with each other. For instance, they posited that the existence of interorganizational systems should provide a building block for additional IT implementations and innovations. In turn, this would lead to better information sharing among IDS participants and significant improvements in information quality as learning and interaction occurred across the different IDS entities. Finally, better information sharing and information quality should then lead to greater improvements in financial and quality outcomes over time (Payton and Ginzberg, 2001).

Further evidence of the value of increased tolerance for change was presented in a 2004 study of decision support systems (DSS) for physician control (Kohli and Kettinger, 2004). In this action research study, hospital administrators worked with physicians to implement a DSS that could provide information regarding cost of care, length of stay, and patient satisfaction. Early versions of this application met with resistance and complaint. However, as physician use of the DSS increased over a period of a few years, the level of physician-led innovation also increased, resulting in the addition of new fields and new reporting capabilities. As a result of continued innovation and use of the DSS, physician practices were changed, business processes were improved, and the hospital realized dramatic cost reductions, significant reductions in length of stay, and improved hospital profitability (Kohli and Kettinger, 2004). 
Because increasing tolerance for change generally results in more successful IT innovation and business process change over the long term, the results of higher tolerance for change are more likely to be realized in late growth and mature IDSs. In these later stages, users have experienced successful IT and organizational change as the IDS has evolved across the life cycle, thus increasing the likelihood that strategic fit may be achieved at an appropriate level for the IDS. On the contrary, those in emergence or early growth IDSs may resist change out of fear and uncertainty of the impact to them individually (Ahadi, 2004). As Ahadi (2004) points out, one of the primary reasons for the failure of both IT and organizational change efforts is a low tolerance for change among the affected parties. He attributes this low tolerance for change to skepticism and fear, particularly in regard to the security of the employee's position in the firm. Thus, because high tolerance for change has been linked to successful business and IT change efforts which resulted in significant performance improvements (Ahadi, 2004), these performance improvements should be greater among IDSs in the late growth and maturity stages.

Centralized IT and business management is defined as the establishment of a core body of management charged with oversight and control of the business and IT interests of the IDS as a corporate unit. IT and business management are addressed simultaneously, as strategic fit depends upon complementary, consistent management structures across both business and IT (Henderson and Venkatraman, 1993). As table 3 describes, centralized IT and business management appears to be most prevalent in the later stages of IDS development, particularly among those in the maturity stage. Prior research credits centralized management with a greater impact on financial and quality performance than decentralized management structures (Venkatraman, 1994; Payton and Ginzberg, 2001; Ahadi, 2004; Weiner et al, 2004).

For instance, among the IDSs in the earlier development stages identified by Weiner et al (2004) in their study of clinical information system implementation, the lack of perceived IT value seemed to stem to a large degree from a lack of management coordination and collaboration. Interview participants noted the decentralized and autonomous management structure of the early stage IDSs, as opposed to the more centralized, coordinated management structure of the later stage IDSs. Particularly within the IDSs in the maturity stage, a sense of systems thinking and centralized coordination and control seemed to result in improved IDS performance and greater perceived value for the users. As table 3 describes, having adapted the work of Weiner et al (2004) in the development of the proposed conceptual life cycle framework, we would anticipate similar results to be observed among IDSs across the various stages of the framework.

Turning to the other foundational study for the proposed life cycle framework, Venkatraman (1994) refers frequently to management coordination, control, and coherence as critical enablers of change throughout his study of IT-enabled business transformation. Each of these terms describes an attribute of centralized management of both IT and business. In his study, he notes that many firms over the past decade have attempted some degree of business restructuring using IT as an enabler; yet, most approached the restructuring in silos of single functions, such as the marketing department, the accounting department, and other individual departments or units within the firm. Venkatraman (1994) posits that while these independent restructuring efforts may result in improved operational efficiency, the lack of centralized management and oversight of these projects will hinder the firm's ability to fully realize the greater benefits of an enterprise wide IT-enabled business transformation.

This study suggests that similar results may be expected across IDSs in the different life cycle stages. Those in the emergence and early growth stages, with decentralized IT and business management, may expect some degree of operational efficiency improvement through IT and business transformation. However, those in late growth and maturity, where centralized management of IT and business are more prevalent, should reap greater performance benefits as a result of the centralized management of IT, business, and related transformations.

Interestingly, in a recent study of organizational enablers of business process reengineering, Ahadi (2004) suspected a possible shift in thinking among contemporary researchers regarding the value of centralized IT and business management. Suggesting that the trend may be shifting toward decentralized management structures, the author hypothesized that centralized business and IT management would negatively impact the firm's ability to successfully implement IT and business process changes, thereby also negatively impacting performance. Testing this hypothesis on a sample of firms representing two different industries, the results revealed a significant positive 
relationship between centralized management and successful business process changes that, in turn, led to measurable improvements in both financial and quality outcomes (Ahadi, 2004). Ahadi then offers explanation of these findings by emphasizing the idea that business process engineering initiatives must be well defined before the project is conducted. And, in that regard, because business process reengineering efforts cross functions, divisions, and processes, these efforts must be managed by a centralized core of senior management personnel with comprehensive knowledge across the different functions and organizations.

In their 1990 study of IT implementation, Cooper and Zmud examined the impact of task-IT alignment during two phases of the IT implementation stage model, namely adoption and infusion. While alignment of specific tasks and supporting IT resources was found to have a significant relationship to IT adoption for multiple layers of organizational complexity, lack of empirical support was found for the relationship between task-IT alignment and infusion. Cooper and Zmud (1990) suggest this lack of support may be due to the need for increased centralized management support during the infusion stage. The authors argue that upper level management must be committed to the project and must actively participate in centralized, coordinated control of the project, particularly in instances where both the organizational processes and the supporting IT resources are quite complex in nature.

As summarized in table 3, the above discussions lend support to the importance of centralized management in late growth or mature IDSs, where the IDS is organizationally more complex and comprehensive and the supporting IT systems are inter-organizational and ERP systems. Centralized management of both business and IT may be more critical in these stages if IT implementation is to successfully move forward through the infusion stage. Without the ability to successfully implement appropriate IT resources, strategic fit of business and IT cannot be reached at any level of IDS development. This issue is then further compounded in the later stages of development, where complexity of structure and IT are most predominant, thus placing greater emphasis on the need for centralized management in these later stages.

Formalized planning is defined as the presence of a formal, documented process for strategic and tactical planning of both IT and business initiatives. Again, as with centralized management, both business and IT planning are grouped together as consistency and coherence of the two are crucial for strategic fit realization. The issue of planning as an antecedent to IT success has been empirically tested and supported in a number of different settings. Consistently, researchers have demonstrated a positive relationship between formal planning and improved firm performance (Ein-Dor and Segev, 1978; Sabherwal, 1999; Byrd et al, 2006). In particular, researchers have addressed the need for coordinated and formalized planning of both business and IT strategies to more fully achieve strategic fit (Venkatraman, 1994; Savitz et al, 2000; Weiner et al, 2004).

Regarding IT planning procedures and policies, Weiner et al (2004) examined the relationship between planning procedures and IT implementation among IDSs at varying levels of development using extensive case studies of five IDSs. Using their IT integration life cycle model, one of the foundational models for our proposed framework, the authors used interviews, reviews of archival records, and observation to place each IDS within the appropriate life cycle stage. Then, examining possible differences between each IDS, one issue of particular interest was the planning process of each IDS. The authors found that IDSs in the mature stage demonstrated a predominantly system-level view of IT. In doing so, these IDSs used steering committees, active system-wide senior management participation, and formal planning policies and procedures regarding IT investments and implementations. As a result of these formal policies and procedures, interview participants in late growth and mature IDSs expressed a high perceived value from the IT implementation. On the contrary, those IDSs in earlier stages, particularly emergence or early growth, demonstrated distributed, autonomous processes in which different departments and facilities made their own IT investment and implementation decisions without consensus across intra- and inter-organizational boundaries. Interview participants in these IDSs were less optimistic regarding the perceived benefits of these implementations.

Similarly, in a study of clinical health improvement network (CHIN) implementations, project participants expressed a concern that a priori systems planning was lacking. The participants identified a need for better planning procedures, needs assessment, and preparation, and suggested that these issues may have made the CHIN implementation process more successful. On the other hand, CIOs in healthcare organizations where the CHIN 
implementation was successful identified the extensive, well-coordinated planning procedures of both the IT and business organizations as key enablers of implementation project success (Payton and Ginzberg, 2001).

Finally, Ahadi (2004) in his study of organizational enablers of business process reengineering, proposed that formal planning and procedures would actually hinder the success of the organizational changes. Contrary to much of the IT planning research, the author viewed formal planning and procedures negatively, particularly in regard to enterprise systems, and felt that the formality restricted active user input. However, statistical analysis of the survey results from a sample of firms representing two industries actually demonstrated a significant positive relationship between formal planning and improved inter-organizational network performance.

As demonstrated in the life cycle framework and in the accompanying profiles (Figure 5 and Table 3), the development of formal planning procedures seems to appear in the late growth or maturity stage, as opposed to the emergence or early growth stage. This may be due in part to the complexity of more mature IDSs and their IT resources and the need to plan effectively for changes and innovations within these IDSs. This may also result from the philosophy of centralized management present in the later stage IDSs.

Many IDSs in late growth or maturity often choose to establish corporate steering teams for IT and business strategy development to improve strategic fit (Savitz et al, 2000; Weiner et al, 2004). These steering teams are charged with the development of detailed, formal plans and procedures for both business and IT innovation and change and, subsequently, oversee the projects from initiation to implementation and support. As the prior literature suggests, IT implementation efforts are generally observed to be more successful as a result of formal planning. This, in turn, should aid in the achievement and maintenance of strategic fit within the late growth and mature IDSs, thus resulting in greater financial and quality improvements than that observed in emergence and early growth IDSs where formal planning is not a part of the IDS profile.

\section{PROPOSITION DEVELOPMENT AND RESEARCH AGENDA}

Proposition Development. A note of concern expressed by Devaraj and Kohli (2003) regarding strategic fit is that too often researchers have ignored complementary organizational practices in studies of IT value to the detriment of the studies' results and the building of theory. Furthermore, researchers argue that simply matching business and IT strategies is insufficient and suggest that the type of actual IT implementation and the level of IT integration must also be appropriate for the degree of organizational integration and the resulting business structure if strategic fit is to be achieved (Henderson and Thomas, 1992). Though most research supports the link between strategic fit and performance improvement at varying levels of analysis, the literature reviewed and discussed in the current manuscript suggests that the strength of these relationships may differ depending upon the business and IT strategies and other complementary variables such as tolerance for change and organizational structure. These suggestions and calls for further research beg the question, "How does the strength of the relationship between strategic fit and financial and quality performance differ when comparing inter-organizational networks at different levels of maturity?"

As discussed in this manuscript, Sabherwal and Chan (2001), in their work on strategic alignment, identified the IT strategy profiles suitable for the organizational categories of defender, prospector, and analyzer (Miles and Snow, 1978). Similar to the stages of the proposed strategic fit life cycle framework, Miles and Snow's (1978) categories represent a scale of structure ranging from a narrow niche with an emphasis on operational efficiency to a very diversified focus with an emphasis on innovativeness, expansion, and flexibility. Thus, Sabherwal and Chan (2001) propose and empirically support the idea that aligning business strategy with the appropriate IT resources does, indeed, result in improved business performance.

Expanding upon these findings even further, Sabherwal and Chan (2001) found that strategic fit had no significant influence on business performance within organizations focused only on stability, operational efficiency, and a narrow niche. Similar to IDSs in the emerging stage, the benefits of strategic fit may not be realized to a significant degree. On the other hand, the authors found support for the relationship between strategic fit and business performance in more tightly integrated organizations focused on innovation, flexibility, and growth. These 
findings suggest that IDSs in the late growth or maturity stage with appropriate IT resources, a greater degree of integration, formalized IT and business planning processes, and a centralized management structure should expect greater financial and quality performance benefits from strategic fit than those in the emergence and early growth stages (Sabherwal and Chan, 2001). propositions:

Thus, the discussions of the current manuscript and the supporting prior literature lead to the following

Proposition 1: When strategic fit is achieved, the relationship between strategic fit and IDS financial performance will be stronger in late growth and maturity life cycle stages than in emerging and early growth stages.

Proposition 2: When strategic fit is achieved, the relationship between strategic fit and IDS quality performance will be stronger in late growth and maturity life cycle stages than in emerging and early growth stages.

Research Agenda. Using the healthcare IDS as a distinct example, the current study has attempted to initiate and promote a research agenda for strategic fit at the inter-organizational network level of analysis, a need acknowledged in the IT literature (Straub et al, 2004). Suggesting an increased complexity with regard to strategic fit at the inter-organizational network level, the study has proposed a life cycle framework of strategic fit across different levels of IDS development. Developed from a blending of the strategic alignment work of Henderson and Venkatraman (1993) and Venkatraman (1994), and the IT integration life cycle (Weiner et al, 2004), the conceptual framework and associated strategic fit profiles find theoretical support in the research literature. Thus, thorough, theoretically sound, empirical studies of strategic fit at the inter-organizational network level of analysis are warranted and needed, particularly in light of the increasing importance of these arrangements in many industries. In particular, research is needed to develop and empirically test measurement models of the strategic fit life cycle, leading to expansion, adaptation, and refinement of the life cycle framework across a number of different industries.

Can we extend theories and findings supported at the firm level of analysis to the inter-organizational network? Within the healthcare industry, in many instances of IDS development, the hospital remains the central, primary entity. In fact, many IDSs are owned and operated by a hospital organization (Dowling, 1997; Young and McCarthy, 1999). Thus, suggesting that across a number of industries a central organization most likely serves as the primary entity of the inter-organizational network, the value of strategic fit at the firm level of analysis may inform propositions and research for the inter-organizational level. Moreover, research suggests that the use of measures readily available at the inter-organizational network level of analysis should be considered in combination with appropriate aggregate measures from the firm level of analysis to provide a more comprehensive measure of inter-organizational network performance (Straub et al, 2004).

Because IT research, and in particular strategic fit, research is lacking at the inter-organizational network level, again we must build upon lower-level findings and theories to begin to establish a body of knowledge and theory for this higher level of analysis. It is no longer sufficient to address IT value only at the firm level in light of a changing business economy and the increasing number of inter-organizational networks developing across many industries. Based on the evidence presented in past literature and the consistently positive results regarding strategic fit value at the firm level, it is reasonable to believe that strategic fit can indeed add value at the inter-organizational network level of analysis. However, further empirical research is needed to assess how and to what extent strategic fit can provide value for the IDS and other inter-organizational networks.

The current study provides a conceptual basis from which to proceed with future research to extend and refine the proposed life cycle framework across a number of industries and levels of inter-organizational network development. However, as suggested in the current study, researchers must account for the differences across various inter-organizational networks, even within the same industry. The degree of strategic fit value has been proposed to increase as the organizational dynamics of structure, integration, governance, and the like differ among inter-organizational networks at different stages of the life cycle framework. Thus, the composition and evolution of the inter-organizational network adds an additional layer of complexity to this research stream; it is important to examine and capture these differences to better inform both research and practice. 
Are there additional attributes of the life cycle framework that should be identified? As stated in the current study, the four attributes presented in this work are important elements of the strategic fit profiles for each life cycle stage of the inter-organizational network as identified from the work of Venkatraman (1994), Savitz et al (2000), and Weiner (2004). While directed at the healthcare IDS, these attributes should be generalizable across many industries, as inter-organizational networks must consider management structure, planning processes, IT resources, and the like as a part of the development and evolutionary process, regardless of the industry. In addition, no ranking of importance has been placed on each attribute, as the current study proposes the need for achieving appropriate levels of each attribute if strategic fit is to be more fully realized within each life cycle stage. Thus, the attributes presented in the current study should serve as a foundation upon which to explore and identify additional attributes of strategic fit and inter-organizational success. In addition to general attributes applicable across a number of industries, future research should also investigate attributes specific to a particular industry. Perhaps there is a level of importance that can be placed on each attribute across a variety of different industries and settings. Over time, these actions together will foster the development of comprehensive and well-developed theories of strategic fit for the inter-organizational network while also informing the practitioner community.

What are the challenges for empirical assessment of the strategic fit life cycle proposed in this study? Although the framework presented in the current study is largely conceptual and exploratory, it has been developed from significant theory, empirical evidence, and long-standing models of strategic fit. The next step, therefore, is to begin to build a body of knowledge, both theoretical and empirical, to extend firm level evidence to the interorganizational network level of analysis. As the framework suggests, there is increased complexity at this level. Thus, we must develop logical, well-planned methodologies to place inter-organizational networks along the development life cycle. From there, we can begin to make comparisons across the different stages and to gather empirical data to further develop, extend, and refine the life cycle framework. In turn, we should be able to extend these concepts and findings across many different industries and inter-organizational arrangements.

Though the current study is conceptual in nature, the framework presented here should serve as a catalyst for an agenda of empirical research on the value of strategic fit for the inter-organizational network. As organizations in many industries struggle to gain or maintain market position, provide better quality products and services, and improve financial performance, many are looking to inter-organizational arrangements as a means of achieving strategic advantage. Therefore, it is crucial that IT researchers consider this level of analysis in future research to support today's business environment and the new business models emerging within this environment.

What are the implications of this research for the practitioner community? The current study has laid a foundation for future research into the differing relationships between business-IT strategic fit and financial and quality performance across a life cycle framework of inter-organizational network development. For IDS management, the framework and associated propositions should provide motivation for the continued pursuit of inter-organizational network diversity and comprehensiveness. By first pinpointing the IDS's position on the strategic fit framework and then assessing the goals of the IDS, the framework and associated profiles can aid IDS management in strategizing a plan for achieving those goals. The same steps may also be taken to evaluate competitors within the industry. As Venkatraman (1994) suggested with his IT-Enabled Business Transformation Model, the results of competitor analysis using a framework such as that proposed in this study may then be used to gain commitment to change among network participants if competitive positioning is to be acquired or maintained. While the evolution from one stage to the next requires investments of both time and money, the benefits of strategic fit in late growth and mature IDSs are anticipated to be greater than those of emergence and early growth IDSs. Thus, over the long term, through successful organizational and IT integration, increasing tolerance for change, centralization of management, and the formation of formal planning processes, the improvements to patient care quality and financial performance sought out by healthcare IDSs should be more readily attainable. Finally, as empirical evidence is discovered and measurement models are developed and tested, this additional evidence of the value of strategic fit in more mature inter-organizational networks should enable managers to better initiate and gain support for continued restructuring and growth. 


\section{CONCLUSION}

The current study has merged theories and concepts from both the IT and healthcare reference disciplines in an attempt to highlight the research needs and potential that exists regarding the value of strategic fit for the interorganizational network. Using the Strategic Alignment Model (Henderson and Venkatraman, 1993), the IT-Enabled Business Transformation Framework (Venkatraman, 1994), and the IT Integration Life Cycle (Weiner et al, 2004), this study has proposed a life cycle framework of strategic fit for the inter-organizational network, using the healthcare IDS as a distinct example. Through the review of past IT and strategic fit literature, a profile of strategic fit for each level of inter-organizational network development has been proposed. In addition, the study has proposed that the value of strategic fit should be greater among more mature inter-organizational networks than among those in earlier stages. A call for empirical support, through the development and testing of measurement models, for the strategic fit life cycle framework are made, and an agenda for strategic fit research at the interorganizational network level of analysis is presented.

\section{REFERENCES}

1. Ahadi, H. R. 2004. An examination of the role of organizational enablers in business process reengineering and the impact of information technology. Information Resources Management Journal, 17(4), 1-19.

2. Barua, A., Kriebel, C. H., and Mukhopadhyay, T. 1995. Information technologies and business value: An analytic and empirical investigation. Information Systems Research, 6(1), 3-23.

3. Borys, B., and Jemison, D.B. 1989. Hybrid arrangements as strategic alliances: Theoretical issues in organizational combinations. Academy of Management Review, 14(2), 234-249.

4. Byrd, T.A., Thrasher, E.H., Lang, T., and Davidson, N. 2006. A process-oriented perspective of IS success: Examining the impact of IS on operational cost. Omega, 34(5), 448-460.

5. Chan, Y.E., Huff, S.L., Barclay, D.W., and Copeland, D.G. 1997. Business strategic orientation, information systems strategic orientation, and strategic alignment. Information Systems Research, 8(2), 125-150.

6. Conrad, D.A., and Shortell, S.M. 1997. Integrated health systems: Promise and performance. Integrated Delivery Systems: Creation, Management, and Governance, D. A. Conrad (ed.), Health Administration Press, Chicago, IL.

7. Cooper, R.B., and Zmud, R.W. 1990. Information technology implementation research: A technological diffusion approach. Management Science, 404-420.

8. Deluca, J.M., and Enmark, R. 2002. The CEO's Guide to Healthcare Information Systems, John Wiley \& Sons, Inc., San Francisco, CA.

9. Devaraj, J.M., and Kohli, R. 2003. Measuring information technology payoff: A meta-analysis of structural variables in firm-level empirical research. Information Systems Research, 14(2), 127-145.

10. Dowling, W.L. 1997. Strategic alliances as a structure for integrated delivery systems. Integrated Delivery Systems: Creation, Management, and Governance, D. A. Conrad (ed.), Health Administration Press, Chicago, IL.

11. Ein-Dor, P., and Segev, E. 1978. Strategic planning for management information systems. Management Science, 24(15), 1631-1641.

12. Friedman, C.P., and Wyatt, J.C. 1997. Evaluation Methods in Medical Informatics, Springer-Verlag, Inc., New York, NY.

13. Henderson, J.C., and Thomas, J.B. 1992. Aligning business and information technology domains: Strategic planning in hospitals. Hospital and Health Services Administration, 37(1), 71-87.

14. Henderson, J.C., and Venkatraman, N. 1993. Strategic alignment: Leveraging information technology for transforming organizations. IBM Systems Journal, 28(2,3), 472-499.

15. Kohli, R., and Kettinger, W.J. 2004. Informating the clan: Controlling physicians' costs and outcomes, MIS Quarterly, 28(3), 363-394.

16. Li, L.X., and Collier, D.A. 2000. The role of technology and quality on hospital financial performance: An exploratory analysis. International Journal of Service Industry Management, 11(3), 202-224.

17. Melville, N., Kraemer, K., and Gurbaxani, V. 2004. Information technology and organizational performance: An integrative model of IT business value. MIS Quarterly, 28(2), 283-322. 
18. Miles, R.E., and Snow, C.C. 1978. Organizational Strategy, Structure, and Process, McGraw-Hill, New York, NY.

19. Ndede-Amadi, A.A. 2004. What strategic alignment, process redesign, enterprise resource planning, and ecommerce have in common: Enterprise-wide computing. Business Process Management Journal, 10(2), 184-199.

20. Payton, F.C., and Ginzberg, M.J. 2001. Interorganizational healthcare systems implementations: An exploratory study of early electronic commerce initiatives. Healthcare Management Review, 26(2), 20-32.

21. Rosow, E., and Grimes, S.L. 2003. Technology's implications for healthcare quality. Nursing Administration Quarterly, 27(4), 307-317.

22. Sabherwal, R. 1999. The relationship between information system planning sophistication and information system success: An empirical assessment. Decision Sciences, 30(1), 137-167.

23. Sabherwal, R., and Chan, Y. E. 2001. Alignment between business and IS strategies: A study of prospectors, analyzers, and defenders. Information Systems Research, 12(1), 11-33.

24. Savitz, L.A., Kaluzny, A.D., and Kelly, D.L. 2000. A life cycle model of continuous clinical process innovation. Journal of Healthcare Management, 45(5), 307-316.

25. Smith, A.E., and Swinehart, K.D. 2001. Integrated systems design for customer focused healthcare performance measurement: A strategic service unit approach. International Journal of Health Care Quality Assurance, 14(1), 21-28.

26. Straub, D., Rai, A., et al. 2004. Measuring firm performance at the network level: A nomology of the business impact of digital supply networks. Journal of Management Information Systems, 21(1), 83-114.

27. Venkatraman, N. 1994. IT-enabled business transformation: From automation to business scope redefinition. Sloan Management Review (Winter), 73-87.

28. Weiner, B.J., Savitz, L.A., Bernard, S., and Pucci, L.G. 2004. How do integrated delivery systems adopt and implement clinical information systems. Healthcare Management Review, 29(1), 51-66.

29. Wickramasinghe, N., and Ginzberg, M.J. 2001. Integrating knowledge workers and the organization: The role of IT. International Journal of Healthcare Quality Assurance, 14(6/7), 245-253.

30. Young, D.W., and McCarthy, S.M. 1999. Managing Integrated Delivery Systems: A Framework for Action, Health Administration Press, Chicago, IL, 